\title{
Assessment of clinical immunogenicity of inotuzumab ozogamicin in patients with non-Hodgkin lymphoma and acute lymphoblastic leukemia
}

\author{
Darshana Jani $i^{*}$ (D), John Nowak², Ying Chen ${ }^{3}$, Joseph Boni ${ }^{4}$ and Boris Gorovits ${ }^{2}$
}

\begin{abstract}
Introduction: Inotuzumab ozogamicin (InO) is an antibody-drug conjugate composed of a recombinant, humanized immunoglobulin type G, subtype 4 (lgG4) antibody covalently bound to a semisynthetic derivative of calicheamicin via an acid-labile linker. It was developed for the treatment of relapsed or refractory non-Hodgkin lymphoma (NHL) and acute lymphoblastic leukemia (ALL). Based on the perceived relatively low immunogenicity risk for this product, a standard approach to immunogenicity testing was utilized during the clinical studies. This manuscript describes the analytical aspects of antibody measurement and highlights the immunogenicity data from clinical studies in patients with hematologic malignancies.
\end{abstract}

Methods: Anti-drug antibodies (ADAs) were determined using an enzyme-linked immunosorbent assay for patients with NHL and a bridging electrochemiluminescence assay for patients with ALL. ALL patients who tested positive for ADA were also tested for neutralizing antibodies (pivotal studies only) using a cell-based assay.

Results: Immunogenicity assays were validated per current industry practice and regulatory guidelines. Positive ADAs were observed in 7 of 164 (4\%) patients with ALL during the pivotal trial. Neutralizing antibodies were not detected in any patients with positive ADAs. No ADAs were detected during the phase I/II ALL study. In NHL studies, antibodies to InO were observed in 27 of 630 (4\%) patients. InO clearance was similar between ADA-positive and ADA-negative ALL patients.

Conclusion: Standard immunogenicity strategy provided data to evaluate impact on InO efficacy, pharmacokinetics, or other clinical parameters in patients. The incidence of ADA to InO is low and is not clinically meaningful.

Keywords: Anti-drug antibody, Immunogenicity, Neutralizing antibody, Inotuzumab ozogamicin (InO), Pharmacokinetics, Calicheamicin, Non-Hodgkin lymphoma, Acute lymphoblastic leukemia

\section{Background}

A common concern with protein-based therapeutics is induction of an immunogenicity response, which is commonly evaluated by detection of anti-drug antibodies (ADAs). The assessment of ADA development is therefore an important aspect of the drug development process and is particularly relevant during evaluation of drug safety and efficacy in early-phase clinical trials. The successful evaluation of immunogenicity and potential clinical sequelae is dependent on the access to

\footnotetext{
* Correspondence: Darshana.Jani@pfizer.com

${ }^{1}$ Pfizer Inc, 610 N. Main Street, Cambridge, MA 02142, USA

Full list of author information is available at the end of the article
}

appropriate methods of detection and characterization of the biotherapeutic specific antibodies.

Antibody-drug conjugates (ADCs) comprise a class of biotherapeutics that combines the targeted delivery capability of a monoclonal antibody (mAb) with a cytotoxic agent (Alley et al., 2010; Teicher \& Chari, 2011) and therefore require the evaluation of immunogenicity in clinical protocols. Inotuzumab ozogamicin (InO; CMC544; $\mathrm{BESPONSA}^{\circ}$, Pfizer) is an ADC composed of a recombinant, humanized anti-CD22 monoclonal immunoglobulin G4 (IgG4) antibody (G544) covalently bound to a semisynthetic derivative of calicheamicin $(\mathrm{N}$ acetyl- $\gamma$-calicheamicin dimethyl hydrazide $[\mathrm{DMH}]$ ) via 
an acid-labile 4-(4'-acetylphenoxy) butanoic acid linker (Fig. 1). The payload of $\mathrm{InO}, \mathrm{N}$-acetyl- $\gamma$-calicheamicin $\mathrm{DMH}$, is a DNA minor groove-binding cytotoxic natural product that induces double-strand DNA breakage (Zein et al., 1988; Shor et al., 2015). The anticancer activity of InO is based on the binding of the ADC to CD22-expressing cells followed by internalization of the ADC-CD22 complex and the intracellular release of $\mathrm{N}$-acetyl- $\gamma$-calicheamicin $\mathrm{DMH}$ via hydrolytic cleavage. Binding of $\mathrm{N}$-acetyl- $\gamma$-calicheamicin $\mathrm{DMH}$ to DNA induces disruption of double-strand DNA, resulting in cell cycle arrest and apoptotic death of the cells (Shor et al., 2015).

Over the course of InO drug development, 2 studies-a pivotal phase 3 study and a phase $1 / 2$ study - were conducted with single-agent InO in patients with relapsed or refractory B-cell acute lymphoblastic leukemia (ALL) (Kantarjian et al., 2016; DeAngelo et al., 2017). Multiple studies were conducted with InO in patients with relapsed or refractory non-Hodgkin lymphoma (NHL) with single-agent InO (Advani et al., 2010), with InO in combination with rituximab (Fayad et al., 2013), and with InO in combination with rituximab and chemotherapy (Ogura et al., 2016).

Our integrated approach to measure the immunogenicity of InO consisted of an assessment of pertinent factors affecting the immunogenicity risk coupled with crafting a robust bioanalytical strategy to assess the critical aspects of potential clinical significance. Product-related factors, patient-related factors, and treatment-related factors, which may contribute to the immunogenicity risk profile of a biotherapeutic (Koren et al., 2002), were thoughtfully evaluated during the development cycle of InO ADC. InO is composed of $100 \%$ human constant regions in both heavy and light chains of the antibody, and 100\% human framework regions of the variable domains in both heavy and light chains of the antibody. The point mutation (S229P) in the hinge region, intended to stabilize covalent dimerization of the heavy chains, has been included in the sequence of other monoclonal antibody-calicheamicin conjugates, including the formerly licensed product gemtuzumab ozogamicin (MYLOTARG ${ }^{\mathrm{m}}$, Pfizer). Therefore, based on

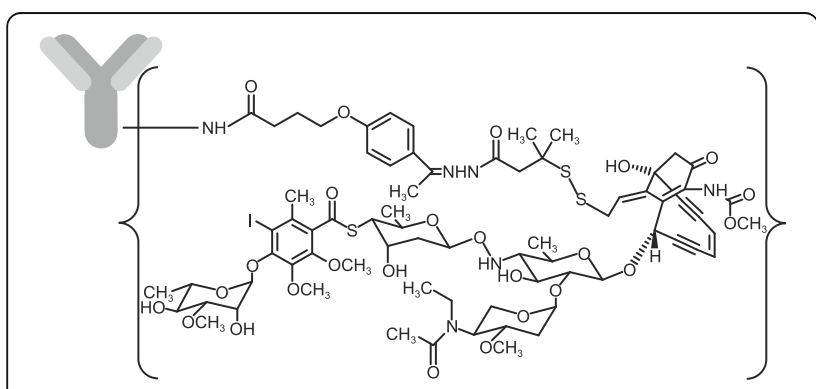

Fig. 1 Chemical structure of inotuzumab ozogamicin its high level of sequence homology to other human immunoglobulins, the sequence of the antibody moiety of $\mathrm{InO}$ is not expected to confer increased risk of immunogenicity relative to other monoclonal antibody therapeutics. The calicheamicin moiety of InO contains carbohydrate structures that may react with IgM anticarbohydrate antibodies present in some patients. Thus, some patients may have pre-existing antibodies reactive with InO. The biochemical and biophysical characterization of manufacturing batches demonstrated a low level of species such as aggregates, degraded forms, and impurities which are thought to contribute to the immunogenicity of administered proteins. Because of the intravenous administration of InO, the limited duration of administration, and the immunosuppressive effect of the combined therapy in NHL studies, the potential for induction of immune responses to $\mathrm{InO}$ was considered to be low. The potential for anti-InO antibodies, should they develop, to cause serious clinical consequences has also been assessed throughout the clinical studies. Because $\mathrm{InO}$ is a monoclonal ADC with no endogenous counterpart, any pre-existing antibodies or antibodies that develop may affect the anti-tumor effect of InO; however, the only potential safety consequences are likely to be antibody-mediated hypersensitivity responses, which occur rarely in patients treated with biopharmaceutical products.

Based on the perceived relatively low immunogenicity risk for this product, a standard approach to immunogenicity testing was utilized during the clinical studies. Immunogenicity response to $\mathrm{InO}$ was measured using two separate bridging platforms in NHL and ALL studies. During early NHL studies, immunogenicity response was measured using an enzyme-linked immunosorbent assay (ELISA) platform, which was considered a gold standard at the time, for the detection of anti-InO or anti-rituximab antibodies. Independent anti-InO and anti-rituximab ELISA methods were developed and validated as per the scientific experience and best practices of laboratories where assays were developed. In the recent ALL studies, a Meso Scale Discovery (MSD) based bridging electrochemiluminescence (ECL) assay was developed and validated as per the regulatory expectations and current industry white papers (Center for Drug Evaluation and Research, US Food and Drug Administration, 2009; Committee for Medicinal Products for Human Use, 2007; Hoofring et al., 2013; Jani et al., 2015; Shankar et al., 2008). Similar bridging assay platforms have successfully been used for other approved ADCs (Carrasco-Triguero et al., 2013). The antibody response was also characterized to determine the specificity for binding to the G544 antibody or calicheamicin moieties of InO. Antibody response to InO was characterized for the domain specificity as well as the neutralizing activity (neutralizing assay was performed only for ALL pivotal studies). 
Here, the technical aspects of ADA measurement are described, and the immunogenicity data from the clinical studies in patients with hematologic malignancies are reported. To our knowledge, this is the first publication describing a cell-based neutralizing antibody assay to support the approval of a therapeutic ADC.

\section{Methods}

\section{Study drug and sample population}

Inotuzumab ozogamicin anti-CD22 antibody G544 conjugated with calicheamicin was generated at Pfizer Inc. Rituximab was purchased from Myoderm Medical Supply (Norristown, PA), and biotinylated rituximab was prepared in assay buffer at Pfizer. InO was studied in patients with relapsed or refractory NHL (9 studies) (Advani et al., 2010; Fayad et al., 2013; Ogura et al., 2016) or ALL (2 studies) (Kantarjian et al., 2016; DeAngelo et al., 2017). The sample collection schedules for ADAs are described in Table 1.

\section{Electrochemiluminescence-based binding antibody assay} in support of acute lymphoblastic leukemia studies The MSD platform-based bridging ECL assay was developed to detect and titer immunoglobulins present in serum that specifically bind to InO. For ALL clinical studies, determination of anti-InO antibodies consisted of 4 sequential steps: (1) screening, (2) confirmation, (3) titer determination, and (4) antibody specificity characterization (to determine specifity for G544 and calicheamicin-BSA). The basic assay procedure, as diagrammed in Fig. 2, was the same for all assays.

\section{Critical reagents}

Inotuzumab ozogamicin was conjugated with ruthenium (II) trisbipyridine, N-hydroxysuccinimide ester (TAG; MSD, Gaithersburg, MD) at a 20:1 ratio or with biotin at a 15:1 ratio according to the manufacturer's instructions. Rabbit (Rb) anti-G544 and anti-calicheamicin polyclonal antibodies were used as positive controls (PCs). For the screening assay, high and low PCs were prepared using $\mathrm{Rb}$ anti-G544 serum at 1:75 and 1:750 dilutions, respectively, in the assay matrix. Affinity purified antibodies were used for sensitivity testing during validation. For the confirmatory assay, $2 \mathrm{PCs}(\mathrm{Rb}$ anti-G544 and $\mathrm{Rb}$ anti-calicheamicin) were used. For cut point determinations, 50 samples of ALL human serum were procured from BioreclamationIVT (Westbury, NY) and stored at $-70{ }^{\circ} \mathrm{C}$ until analysis. Pooled normal human serum was used as the negative control (NC).

\section{Assay performance validation parameters}

Assay validation included assessment of the following parameters: (1) assay cut points (screening, confirmation, and characterization); (2) precision (intra- and interassay); (3) specificity (screening and confirmation assay); (4) sensitivity; (5) selectivity and matrix interference; (6)

Table 1 Immunogenicity sample collection schedule

\begin{tabular}{|c|c|c|c|c|c|c|c|}
\hline Cycle 1 (Predose) $^{\mathrm{a}}$ & Cycle 2 & Cycle 3 & Cycle 4 & Cycle 5 & Cycle 6 & Cycle 7 & EOT \\
\hline \multicolumn{8}{|c|}{ Patients with relapsed or refractory $A L L$ who received single-agent InOb } \\
\hline$x$ & & & $x$ & & & & $x$ \\
\hline$x$ & $x$ & $x$ & $x$ & $x$ & $x$ & & $x$ \\
\hline \multicolumn{8}{|c|}{ Patients with relapsed or refractory $\mathrm{NHL}$ who received single-agent $\ln \mathrm{O}^{c}$} \\
\hline$x$ & $x$ & $x$ & $x$ & $x$ & & $x$ & $x$ \\
\hline$x$ & $x$ & $x$ & $x$ & $x$ & & $x$ & $x$ \\
\hline X & & $x$ & & & & & $x$ \\
\hline \multicolumn{8}{|c|}{ Patients with relapsed or refractory NHL who received InO plus rituximabc } \\
\hline & $x$ & $x$ & $x$ & $x$ & & $x$ & $x$ \\
\hline & $x$ & $x$ & $x$ & $x$ & & $x$ & $x$ \\
\hline \multicolumn{8}{|l|}{$x$} \\
\hline$x$ & & & $x$ & & & & $x$ \\
\hline$x$ & $x$ & $x$ & $x$ & $x$ & $x$ & & $x$ \\
\hline \multicolumn{8}{|c|}{ Patients with relapsed or refractory NHL who received InO plus rituximab plus chemotherapy ${ }^{c}$} \\
\hline$x$ & & & $x$ & & & & $x$ \\
\hline \multicolumn{8}{|c|}{$\begin{array}{l}\text { Samples taken predose for respective treatment cycles } \\
A L L \text { acute lymphoblastic leukemia, } E C L \text { electrochemiluminescence, ELISA enzyme-li } \\
N H L \text { non-Hodgkin lymphoma } \\
\text { a Before first InO treatment. May have been omitted if sample taken at screening } \\
{ }^{b} E C L \text { assay } \\
{ }^{c} E L I S A\end{array}$} \\
\hline
\end{tabular}




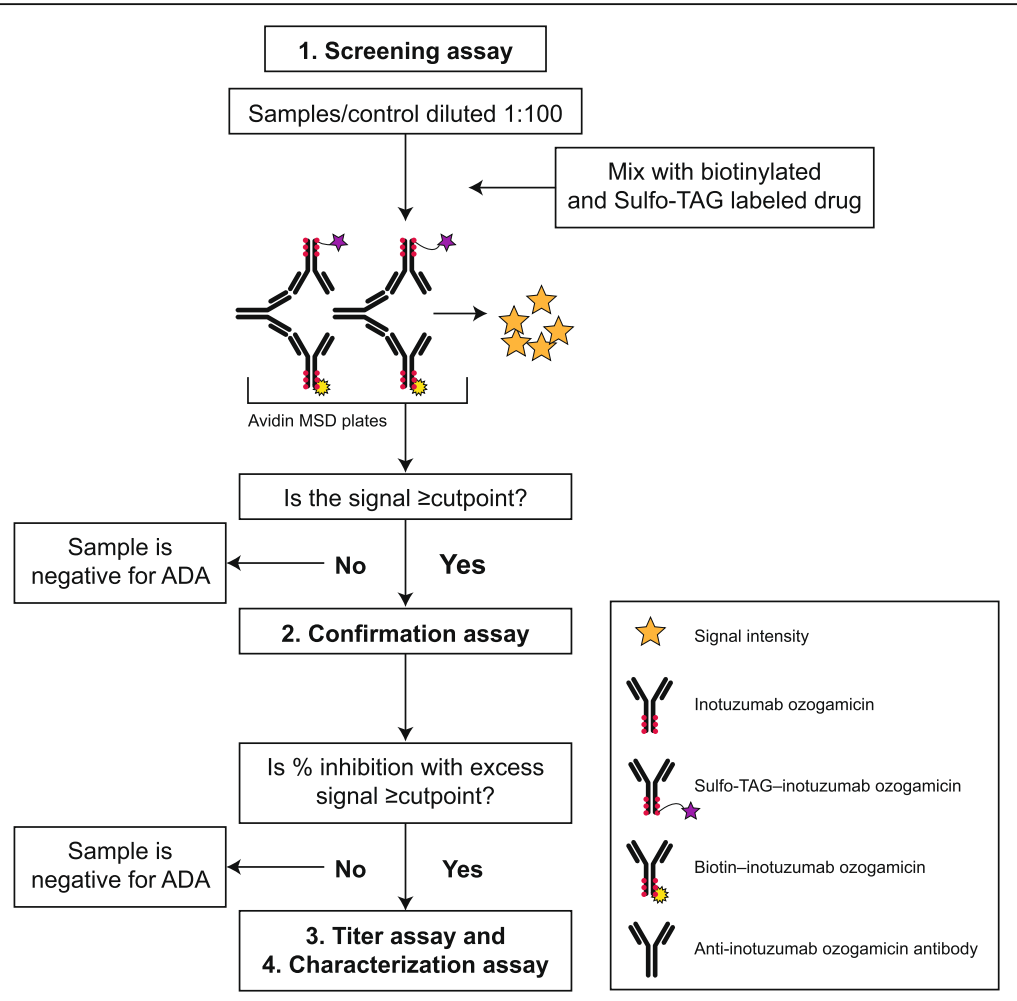

Fig. 2 ECL bioanalytical method for the detection of ADAs during ALL studies. ADA = anti-drug antibody; $A L L=$ acute lymphoblastic leukemia; $\mathrm{ECL}=$ electrochemiluminescence; $\mathrm{MSD}=$ Meso Scale Discovery

drug tolerance and stability (freeze/thaw, ambient, and refrigerated); and (7) control range acceptance criteria. The method conforms to US Food and Drug Administration (FDA) guidance (Guidance for Industry: Assay Development for Immunogenicity Testing of Therapeutic Proteins, issued 2009) recommendations for the assay development for immunogenicity testing for therapeutic products (Center for Drug Evaluation and Research, US Food and Drug Administration, 2009) and was validated using standard bioanalytical parameters and target acceptance criteria (Shankar et al. 2008).

The screening and confirmatory assay cut points were statistically determined based on the current industry white papers (Jani et al., 2015; Shankar et al., 2008). A screening cut point was derived from 50 treatment-naive ALL patients (BioreclamationIVT) by targeting a $5 \%$ false-positive rate to minimize potential false-negatives. The assay cut point was derived from the 95th percentile of the log-transformed normalized relative light unit (RLU) values from each plate after removal of statistical outliers (Shankar et al., 2008). For the confirmatory assay, confirmatory cut point was calculated by testing serum samples from 50 treatment-naive patients with ALL (BioreclamationIVT). The serum samples were incubated with an excess amount of InO before analysis in a competitive binding format (Jani et al., 2015). For each sample, the percentage inhibition values in the confirmatory assay were calculated. The confirmatory assay cut point was derived from the 99th percentile of the log-transformed normalized RLU values from each plate. Likewise, characterization cut points were calculated for the G544 and calicheamicin portions of the molecule.

The assay was evaluated for inter-day and intra-day precision based on coefficient of variation $(\% \mathrm{CV})$ with target acceptance of PC endpoint titers $\left(\log _{10}\right)$ from each set of PC (intra-run), and all runs (inter-run) are less than $25.0 \%$. In the drug interference test, the concentration of InO that inhibits the ability to detect PCs was assessed. The drug interference test was performed using anti-G544 at high PC (1:75) and low PC (1:750) concentrations and InO at $0,1,5,10,20$, and $50 \mu \mathrm{g} / \mathrm{mL}$. The highest concentration of InO for which the PC still appeared positive or greater than the plate cut point for each PC was identified. Mass-based assay sensitivity is the concentration of anti-InO antibodies in human serum that will result in a signal equal to the plate cut point. Sensitivity was performed using affinity-purified anti-G544 antibodies and was reported from 3 independent titrations. 
The assay sensitivity was calculated by the following formula:

\section{Sensitivity $=[$ starting antibody concentration $] /$ dilution}

Assay selectivity was measured by calculating $\mathrm{PC}$ recovery, which is the ability of an analytic method to differentiate and quantify the analyte in the presence of other components in the sample. The assay recovery was performed by analyzing $\mathrm{NC}$, buffer, and 10 individual lots of ALL diseased human serum samples spiked with and without high and low PC1 anti-G544 serum antibodies. The matrix selectivity was also assessed by analyzing NC, buffer, and 10 individual lots of ALL diseased human serum samples spiked with and without high and low PC2 anti-calicheamicin antibodies. Stability of PCs and labeled reagents was assessed using the standard criteria of room temperature, $-20{ }^{\circ} \mathrm{C}$, and $-70{ }^{\circ} \mathrm{C}$ storage and 5 freeze/ thaw cycles; additionally, samples were compared with freshly prepared reagents.

\section{Screening assay}

Samples and controls were diluted 1:100 and mixed with an equal volume of a solution containing an equal concentration of ruthenylated (Sulfo-TAGGED) and biotinylated InO labels. Antibodies against $\mathrm{InO}$ were detected because they bridge biotinylated $\mathrm{InO}$ (the capture reagent) to ruthenylated InO (the reporter). The samples and controls were tested in duplicate and dispensed into an avidincoated assay plate (Avidin HB; MSD), where biotinylated InO in the complex bound to the avidin-coated wells. Samples that contained ADAs generated an ECL signal in the presence of a tripropylamine-containing buffer. The signal generated on the plate reader (MSD Sector Imager 6000) was reported as RLU and was proportional to the amount of ADA present. Samples were classified as screened-positive if the average sample signal was greater than or equal to the calculated screening assay cut point. Cut point determination is described within the assay validation section.

\section{Confirmatory assay}

Samples that tested positive in the screening assay were further evaluated in a confirmatory assay, which used excess unlabeled drug in a competitive binding format to demonstrate the specificity of the binding interactions in the antibody-labeled drug complex. All samples were incubated with and without excess InO diluted in serum containing buffer, and the mixture was added to a microtiter plate. The remainder of the confirmatory assay procedure was the same as for the screening assay. For a sample to be confirmed as positive and specific, it had to demonstrate sufficient reduction in signal (percentage inhibition) upon addition of excess drug using the following calculation after average signal from the duplicate was calculated:

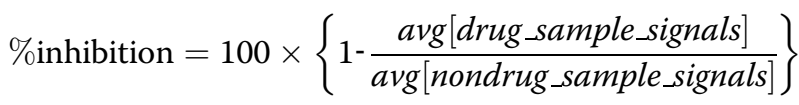

The samples were deemed positive and specific if the percentage inhibition was greater than or equal to the statistically derived confirmatory assay cut point. Samples that were confirmed as positive and specific were further evaluated in titer and domain specificity characterization assays. In this assay, excess drug concentration of $10 \mu \mathrm{g} / \mathrm{mL}$ was selected after testing the range from 0 to $100 \mu \mathrm{g} / \mathrm{mL}$ spiked in $\mathrm{PC}$ and $\mathrm{NC}$.

\section{Titer assay}

A titer was assessed for samples that were confirmed as being positive and specific. The samples were serially diluted 3-fold in pooled normal human serum. The remainder of the assay procedure was the same as the screening assay. A sample's titer was determined using the statistically derived screening assay cut point factor and the mean values of the $\mathrm{NC}$ signals in the assay/plate; a titer was defined as the $\log _{10}$ of the reciprocal of the interpolated dilution at which the sample signal was equal to the cut point. The endpoint titer was calculated using a validated Life Information Management Systems system (ThermoFisher Scientific Watson version 7.4.1 software with Immune Response Module). Briefly, titer values for samples are derived from a plot of assay signal (RLU) versus reciprocal of dilution (RD) that is not visible to the user in the software. To derive endpoint titer, an interpolated value option of software was selected. The software identifies the points immediately before and after the cut point, assuming a straight line between them. The endpoint titer is then derived based on the following equation:

Endpoint $=$ RD_above_CP

$$
+\left\{\frac{[\text { signal_above_CP-signal_at_CP }] \times\left[R D \_b e l o w_{-} C P-R D \_ \text {above_CP }\right]}{[\text { signal_above_CP-signal_below_CP }]}\right\}
$$

\section{Domain specificity characterization assay}

The characterization assay was similar to the confirmation assay, where the samples were incubated with a competitor. In the characterization assay, the competitors were G544 and calicheamicin-BSA. For a sample to be specific for a particular competitor, there had to be reduction in signal (percentage inhibition cut point) upon addition of that competitor. 
Cell proliferation neutralizing antibody assay in support of acute lymphoblastic leukemia studies

\section{Critical reagents}

Pooled normal human serum was used as the NC. The $\mathrm{Rb}$ anti-G544 polyclonal antibody was spiked in the $\mathrm{NC}$ at a 1:250 dilution to be used as a PC. PC working stock solution was prepared in bulk, aliquoted, and stored at - $70{ }^{\circ} \mathrm{C}$. RS4;11, a B-lymphoblastic cell line (ATCC ${ }^{\bullet}$ CRL-1873 ${ }^{\mathrm{rm}}$ ) was obtained from ATCC (Manassas, VA) and maintained over time according to the vendor's instructions. The culture medium RPMI-1640 (Roswell Park Memorial Institute 1640-Gibco), supplemented with fetal bovine serum (ATCC 30-2020) to a final concentration of $10 \%$, was used to maintain the cells at a density ranging from $1 \times 10^{5}$ to $1 \times 10^{6}$ viable cells $/ \mathrm{mL}$ at $5 \% \mathrm{CO}_{2}$ in a $37{ }^{\circ} \mathrm{C}$ cell culture incubator.

\section{Assay performance validation parameters}

Assay validation included assessment of the following parameters: (1) assay cut point; (2) precision (intra-assay and inter-assay); (3) sensitivity; (4) selectivity and matrix interference; (5) drug tolerance; and (6) stability (cell passage numbers, freeze/thaw, ambient, and refrigerated).

\section{Assay cut point determination}

Normality of population distribution was evaluated before and after outlier exclusions using JMP ${ }^{\circledR}$ Statistical Discovery Software, version 10.0 (SAS Institute Inc., Cary, NC) for screening analysis. Assay cut point determination is described above. The individual samples from the treatment-naive ALL diseased human serum population $(n=50)$ were each analyzed at a minimum of 3 independent runs for screening for $\geq 2$ days with $\geq 2$ analysts. A cut point factor was calculated by dividing the plate cut point by the mean response of $\mathrm{NC}$ for each plate and averaging each plate cut point factor. Normality of population distribution was evaluated before and after outlier exclusions using JMP Statistical Discovery Software, version 10.0 (SAS Institute Inc.) for screening analysis.

\section{Assay performance parameters}

Similar to the binding antibody assay, the assay was validated using standard bioanalytical parameters and target acceptance criteria in addition to cut point determination. Precision of the method was expressed as \%CV from analyzing replicates of PCs. The assay was considered precise if the \%CV of $\mathrm{PC}$ endpoint $\log _{10}$ titer from each set of PCs (intra-assay) and all accepted applicable runs (inter-assay) were $<30 \%$. In the drug interference test, the concentration of $\mathrm{InO}$ that inhibited the assay detection of PCs was assessed. PC1 1:250 was preincubated in the presence of InO at different concentrations $(0,0.063,0.125,0.25,0.5,1,2$, and $4 \mu \mathrm{g} / \mathrm{mL})$ before minimum required dilution (MRD). The highest concentration of $\mathrm{InO}$ at which the $\mathrm{PC}$ remained positive was identified. Selectivity was evaluated using the recovery method. The assay recovery was performed by analyzing $\mathrm{NC}$, assay buffer, and 12 individual lots of ALL human serum spiked with and without high positive control (PC1 1:250). Assay sensitivity, measured using affinitypurified Rb anti-G544 PC (surrogate antibody for neutralizing anti-InO antibody), was the concentration that will result in a signal that is equal to the plate cut point. This was determined from 3 independent runs conducted by 2 separate analysts that use affinity-purified anti-G544 antibodies with a known concentration.

Stability was tested for cell passage numbers and standard parameters using PCs. Cell passage stability was evaluated with 2 independent runs; each run included 2 passages of cells with the same $\mathrm{NC}$ and PC preparations on the same plate, 1 passage $\leq 10$ (passages 9 and 10) and the other $\geq 20$ (passages 21 and 22). Stability of PCs was tested at various temperatures. Room temperature stability of Rb anti-G544 antibody (PC1 1:250) in human serum was used as the surrogate to evaluate neutralizing anti-InO antibody stability for the time that the samples were at room temperature during handling and processing. PC1 1:250 aliquots were thawed, kept at room temperature for $21 \mathrm{~h}$, and then stored at $-70{ }^{\circ} \mathrm{C}$ until the day of analysis. Samples were analyzed together with an aliquot of the PC1 1:250 thawed immediately before analysis (0-h control). The stability of Rb anti-G544 antibody (PC1 1:250) in human serum was used as the surrogate to evaluate anti-InO antibody stability in the matrix after 5 freeze/thaw cycles. Individual PC1 1:250 samples were frozen at $-70{ }^{\circ} \mathrm{C}$ (minimum of $24 \mathrm{~h}$ for the first cycle; minimum of $12 \mathrm{~h}$ for subsequent cycles) and thawed unassisted at room temperature for $\geq 1 \mathrm{~h}$ between frozen periods. Samples were analyzed after completion of the fifth cycle together with an aliquot of the PC1 1:250 that was thawed before analysis (1 freeze/thaw cycle). Individual PC1 1:250 samples were frozen at $-20{ }^{\circ} \mathrm{C}$ (minimum of $24 \mathrm{~h}$ for the first cycle; minimum of $12 \mathrm{~h}$ for subsequent cycles) and thawed unassisted at room temperature for $\geq 1 \mathrm{~h}$ between frozen periods. Samples were analyzed after completion of the fifth cycle together with an aliquot of the PC1 1:250 that was thawed before analysis (1 freeze/thaw cycle).

\section{Cell proliferation assay method}

A cell-based assay was used to determine neutralizing anti-InO antibodies in the human serum samples. In this assay, RS4;11 at $1 \times 10^{4}$ cells/well per $80 \mu \mathrm{L}$ medium was incubated with $100 \mu \mathrm{g} / \mathrm{mL} \mathrm{InO}$ and $\mathrm{NC} / \mathrm{PC}$ samples in a sterile 96 -well cell culture plate for $24 \pm 1 \mathrm{~h}$ in a $37^{\circ} \mathrm{C}, 5 \%$ $\mathrm{CO}_{2}$ cell culture incubator. During incubation, ADAs that could neutralize the drug activity protected the cells by 
preventing cell death resulting in increased cell viability. After incubation, the cells were lysed using CellTiter-Glo ${ }^{\circ}$ Luminescent Cell Viability kit (Promega, Madison, WI), and the luminescence was recorded with a SpectraMax L microplate reader (Molecular Devices, Sunnyvale, CA). CellTiter-Glo kit determines the number of viable cells based on the quantitation of adenosine triphosphate, which signals the presence of metabolically active cells. Therefore, the response generated from the microplate reader corresponds to the number of viable cells in the culture. Neutralizing anti-InO antibodies can be determined based on the signals generated from the viable cells, which are directly proportional to the number of neutralizing anti-InO antibodies present in the sample. The antibody endpoint titer is calculated with Watson 7.4.1 Immune Response Module (Thermo Fisher Scientific, Waltham, MA), and the data are presented as endpoint $\log$ titers $\left(\log _{10}\right.$; endpoint titer is defined as the reciprocal of the serum dilution at which the sample response would be equal to the cut point of the assay). The basic assay procedure is diagrammed in Fig. 3.

\section{Enzyme-linked immunosorbent assay-based anti- inotuzumab ozogamicin antibody assay in support of non-Hodgkin lymphoma studies}

An ELISA-based bridging assay was developed to detect and titer immunoglobulins present in serum that specifically bind to the drug. For NHL clinical studies, determination of the presence of ADAs against InO followed a sequential process that included (1) screening and (2) concurrent titer determination and specificity to confirm positive screen assay results.

\section{Critical reagents}

Inotuzumab ozogamicin, biotinylated InO, Rb anti-G544 antiserum, and $\mathrm{Rb}$ anti-calicheamicin antiserum were provided by Pfizer Inc. Rb anti-G544 and anticalicheamicin polyclonal antibodies (diluted in human serum) were used as PCs. Rb anti-G544 PC was tested in a full dilution series from 1:25 to $1: 1: 54,675$ using 3fold serial dilutions. $\mathrm{Rb}$ anti-calicheamicin $\mathrm{PC}$ was tested

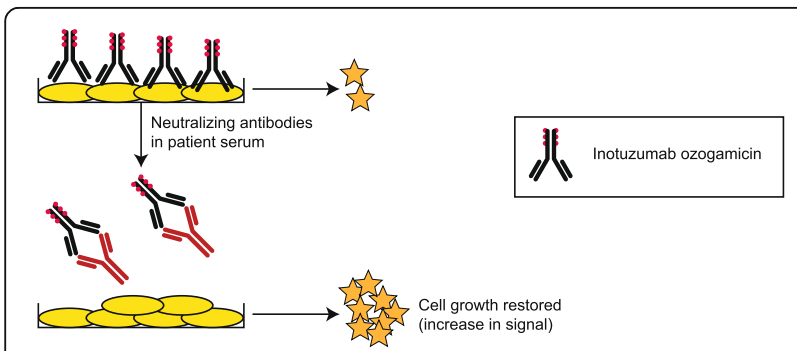

Fig. 3 Detection of anti-drug neutralizing antibodies during ALL studies. In the presence of inotuzumab ozogamicin, apoptosis of RS4;11 cells results in the reduction of signal. $A L L=$ acute lymphoblastic leukemia at 1:25 and 1:75 dilutions. For cut point assessment, 30 samples of normal human serum and 20 samples from patients with NHL were procured commercially and stored at $-70{ }^{\circ} \mathrm{C}$ until analysis.

\section{Assay validation parameters}

Assay validation included assessment of the following parameters: (1) cut point determination, (2) precision (intra-assay and inter-assay), (3) specificity, (4) sensitivity, (5) linearity, (6) drug tolerance, and (7) stability (freeze/thaw and ambient).

\section{Assay cut point}

A cut point factor of 2 was used for clinical sample analysis and approximates 2 to 3 standard deviations (SDs) above the mean of NC samples (data not shown). In order to align with industry benchmarks, the screening cut point was statistically derived by targeting a $5 \%$ false-positive rate following industry guidelines to minimize potential false-negatives. The serum samples from 20 treatment-naive NHL individual samples and 30 normal human serum samples were analyzed 3 times each over 3 days. The assay cut point was derived from the $95 \%$ upper confidence limit after removal of outliers. Because different cut point factors were obtained for the normal human serum and NHL sample populations, the NHL-specific cut point factor was used for clinical sample analysis.

\section{Precision, sensitivity, specificity, stability parameters}

In addition to cut point determination, the assay was validated using standard bioanalytical parameters and target acceptance criteria. The assay was evaluated for inter-day and intra-day precision based on \%CV $<25$ with target acceptance of PC end point $\log _{10}$ titers from each set of PC (intra-run) and all accepted runs (interrun). Mass-based assay sensitivity was assessed using an affinity-purified Rb anti-G544 antibody and was determined as the antibody concentration that resulted in a signal equal to the plate cut point.

Assay specificity was evaluated by eliminating InO coating of wells. The stability of antibodies in this assay was assessed by ambient and freeze/thaw stability of PCs using controls stored at room temperature for $24 \mathrm{~h}$ or after undergoing 3 freeze/thaw cycles; these samples were then compared with freshly prepared reagents.

\section{Screening assay}

Inotuzumab ozogamicin was immobilized on a microtiter plate. After blocking, biotinylated $\mathrm{InO}$ mixed with controls or diluted serum samples was added to the plate and incubated for $2 \mathrm{~h}$. ADAs bound to both immobilized and biotinylated InO were detected by avidin-horseradish peroxidase (HRP) with $3,3^{\prime}, 5,5^{\prime}$ 
tetramethylbenzidine (TMB) enzyme substrate to generate color measured as optical density (OD) values at $450 \mathrm{~nm}$ using a SpectraMax L microplate reader. Rabbit anti-G544 and anti-calicheamicin polyclonal antibodies were used as PCs, and pooled normal human serum was used as the NC. The PC and NC were used to monitor assay performance and verify plate acceptability. Each study sample was initially tested in a screening assay at 1:25 and 1:75 dilutions. This bioanalytical method was used to support 2 initial studies of $\mathrm{InO}$ as single-agent therapy and in 2 initial studies of $\mathrm{InO}$ in combination with rituximab. The method was subsequently revalidated. Upon revalidation, the cut point OD was statistically determined to be 1.48 times the mean of the $\mathrm{NC}$ OD value. This bioanalytical method was used to support later NHL studies. Samples with a screening OD value below the cut point $\mathrm{OD}$ were considered negative, and results were reported as titer $<1.40$ (log of 25 , the assay MRD). Samples with a screening OD value greater than or equal to the cut point OD were reassayed in concurrent titer and specificity assays.

\section{Specificity and titer assays}

The specificity and titer assays were of the same format as the screening assay, except the specificity plate was coated with buffer rather than with InO. Positive screening samples were reassayed in concurrent specificity and titer assays at 8 dilutions (1:25 followed by serial 1:3 dilutions in diluted pooled normal human serum). The remainder of the specificity assay procedure followed was the same as that for the screening assay. For a sample to be confirmed as specific for InO, the log titer on the specificity plate was required to be $<1.40$ (or if $\geq 1.40$, the corresponding titer assay result was required to be $>0.48$ [ $\log$ of 3 , the serial dilution factor] above the specificity assay titer). Antibody titer was defined as the $\log _{10}$ of the reciprocal of the dilution at which the sample OD was equal to the cut point OD. Samples were considered positive for InO if they were determined to be specific for InO and had positive log titer values $(\geq 1.40)$.

\section{Enzyme-linked immunosorbent assay-based anti-rituximab antibody assay in support of non-Hodgkin lymphoma studies}

An ELISA platform-based bridging assay was developed to detect and titer serum anti-rituximab antibodies. For NHL clinical studies, determination of the presence of anti-rituximab antibodies followed a sequential process that included (1) screening and (2) concurrent titer determination and specificity to confirm positive screen assay results. This bio-analytical method was used to support studies of $\mathrm{InO}$ in combination with rituximab and a single study of InO in combination with rituximab plus chemotherapy.

\section{Critical reagents}

A goat antihuman IgG antibody was obtained from Zymed Laboratories, Inc. (Thermo Fisher Scientific) and served as the assay PC. Pooled normal human serum served as the NC.

\section{Assay validation parameters}

Assay validation included assessment of the following parameters: (1) precision (intra-assay and inter-assay), (2) sensitivity, (3) rituximab and InO drug tolerance, (4) stability (ambient and freeze/thaw), and (5) PC acceptance range.

\section{Assay cut point}

A panel of 30 normal human serum samples was tested as part of cut point assessment. A cut point factor of 2 was used for clinical sample analysis. Historically, a cut point factor of 2 was considered to represent approximately 2 to 3 SDs above the mean of NC samples (data not shown).

\section{Precision, sensitivity, specificity, stability parameters}

In addition to cut point determination, the assay was validated using standard bioanalytical parameters and target acceptance criteria. The PC acceptance range was based on \pm 3 SDs around the mean log titer observed in validation. Mass-based assay sensitivity was assessed using a purified goat antihuman IgG antibody and was determined as the antibody concentration that resulted in a signal equal to the plate cut point. The assay sensitivity was calculated by the following formula:

\section{Sensitivity $=[$ Starting antibody concentration $] /$ Dilution}

Assay specificity was evaluated by eliminating rituximab coating of wells.

The stability of antibodies in this assay was assessed by ambient and freeze/thaw stability of PCs by testing controls stored at room temperature for $24 \mathrm{~h}$ or after undergoing 3 freeze/thaw cycles; these samples were then compared with freshly prepared reagents.

\section{Screening assay}

Rituximab was immobilized on a microtiter plate. After blocking, biotinylated rituximab and then controls and diluted serum samples were added to the plate and incubated for $2 \mathrm{~h}$. Anti-rituximab antibodies bound to both immobilized and biotinylated rituximab were detected using streptavidin-HRP with a TMB enzyme substrate to generate colorimetric OD values. The cut point OD was defined as twice the mean of the NC OD value. Each study sample was initially tested in a screening assay at 1:25 and 1:75 dilutions. A sample with a screening OD 
value below the cut point OD was considered negative, and results were reported as titer $<1.40(\log 25)$.

\section{Specificity and titer assays}

Samples with a screening OD value greater than or equal to the cut point OD were reassayed in concurrent titer and specificity assays at 8 dilutions (initially 1:25 and then serial 1:3). The specificity and titer assays were of the same format as the screening assay, except that the specificity plate was coated with buffer rather than rituximab. The specificity assay for anti-rituximab antibodies was carried out in a manner identical to that used for the anti-InO specificity assay. Antibody titer was defined as the $\log _{10}$ of the reciprocal of the dilution at which the sample OD was equal to the cut point OD. Samples were considered positive for rituximab if they were determined to be specific for rituximab and had positive log titer values $(\geq 1.40)$.

The final protocol and informed consent documentation from each study were reviewed and approved by an investigational review board/independent ethics committee at each study site. Each trial was conducted in compliance with the Declaration of Helsinki and the International Council for Harmonisation Good Clinical Practice guidelines. Patients provided written informed consent.

\section{Results}

Due to the route of administration (intravenous), the limited duration of administration, and the immunosuppressive effect of the combined therapy in NHL studies, the potential for induction of immune responses to $\mathrm{InO}$ was considered to be low. A standard tiered approach was used to evaluate immunogenicity response in NHL and ALL studies.

The following assays were used throughout the course of InO drug development.

\section{Electrochemiluminescence antibody assay to support acute lymphoblastic leukemia studies}

The screen cut point factor (SCPF) and confirmatory/ characterization cut point $(\mathrm{CCP})$ were determined using 50 commercially procured ALL serum samples according to proposed methods (Jani et al., 2015; Shankar et al., 2008) (95\% CI for screen cut point [SCP] and 99.9\% CI for CCPs for InO, G544, and calicheamicin-BSA). To obtain the SCP for the assay, the NC signal was multiplied by the SCPF of 1.47. Using a competitive binding assay as described in the Methods section, signal decreases of $59 \%$ and $13 \%$ indicated positive response to InO and G544, respectively. Likewise, signal decreases of $64 \%$ indicated a positive response to the calicheamicin portion of the drug. Overall, validation data suggested that the assay was precise, reproducible, and sensitive for sample testing. Drug tolerance data indicated that the assay was capable of detecting the antibodies in the presence of $50 \mu \mathrm{g} / \mathrm{mL}$ of circulating drug. Because ADCs are designed to bind to cell surface receptors, trough circulating drug concentrations are typically low. In this case, mean trough levels were determined to be $<100 \mathrm{ng} / \mathrm{mL}$, which is not expected to interfere with ADA detection at 75- to 750-fold dilution of the surrogate of polyclonal PC. The results of the validation parameters are highlighted in Table 2.

\section{Cell proliferation neutralizing antibody assay}

The neutralizing SCPF was determined using 50 commercially procured ALL serum samples $(99.9 \% \mathrm{CI})$ based on the scientific practice at the time. To obtain the SCP for the assay, the NC signal was multiplied by the SCPF of 1.24. Assay sensitivity using a polyclonal PC antibody was approximately $580 \mathrm{ng} / \mathrm{mL}$, with drug interference at approximately $1 \mu \mathrm{g} / \mathrm{mL}$ of circulating drug. At trough levels, the detection of PC was approximately $50 \mathrm{ng} / \mathrm{mL}$ at an antibody:drug ratio of approximately 1:2. In addition, cell passage stability was observed up to passage 22 without any impact on neutralizing capabilities

Table 2 Highlights of ECL antibody assay validation characteristics

\begin{tabular}{|c|c|}
\hline PC & $\begin{array}{l}\text { PC1: Rabbit Anti-InO } \\
\text { PC2: Rabbit Anti-CMC } \\
\text { (Payload) Antibody }\end{array}$ \\
\hline \multirow{2}{*}{$\begin{array}{l}\text { PCs in biological matrix } \\
\text { (drug tolerance and } \\
\text { confirmation assay) }\end{array}$} & HPC 1:75 in $100 \%$ serum \\
\hline & LPC 1:750 in $100 \%$ serum \\
\hline $\begin{array}{l}\text { Intra-assay precision } \\
\text { (\%CV of endpoint } \log _{10} \text { titer) }\end{array}$ & $0.8 \%$ \\
\hline $\begin{array}{l}\text { Inter-assay precision } \\
\text { (\%CV of endpoint } \log _{10} \text { titer) }\end{array}$ & $1.2 \%$ \\
\hline $\begin{array}{l}\text { Sensitivity (affinity-purified } \\
\text { polyclonal antibody) }\end{array}$ & $215 \mathrm{ng} / \mathrm{mL}$ (in 100\% serum) \\
\hline Drug interference & $\begin{array}{l}P C \text { at high concentration was } \\
\text { detected in the presence of } \\
50 \mu \mathrm{g} / \mathrm{mL} \text {; PC at low concentration } \\
\text { was detected in the presence } \\
\text { of } 5.0 \mu \mathrm{g} / \mathrm{mL}\end{array}$ \\
\hline $\begin{array}{l}\text { Matrix selectivity (recovery) } \\
\text { with PCs }\end{array}$ & $\begin{array}{l}\text { All unspiked samples generated } \\
\text { signal below the cut point showing } \\
\text { negative result; } 90 \% \text { of ALL lots } \\
\text { tested had recovery between } 75 \% \\
\text { and } 125 \% \text { for both control } \\
\text { antibodies }\end{array}$ \\
\hline \multirow[t]{2}{*}{ Stability (PC1 and PC2) } & 23-h ambient temperature \\
\hline & $\begin{array}{l}5 \text { freeze/thaw cycles at }-70^{\circ} \mathrm{C} \\
\text { and }-20^{\circ} \mathrm{C}\end{array}$ \\
\hline $\begin{array}{l}\text { Stability (biotinylated and } \\
\text { ruthenylated InO } \\
\text { freeze/thaw stability) }\end{array}$ & 5 freeze/thaw cycles at $-70^{\circ} \mathrm{C}$ \\
\hline
\end{tabular}

$\% C V$ coefficient of variation, ALL acute lymphoblastic leukemia, CMC calicheamicin, $E C L$ electrochemiluminescence, HPC high positive control, InO inotuzumab ozogamicin, LPC low positive control, $P C$ positive control 
Table 3 Highlights of neutralizing antibody assay validation characteristics

\begin{tabular}{|c|c|}
\hline PC & Rabbit Anti-InO \\
\hline $\begin{array}{l}\text { Intra-assay precision } \\
\text { (\%CV of endpoint } \log _{10} \text { titer) }\end{array}$ & $6.1 \%$ \\
\hline \multicolumn{2}{|l|}{ Inter-assay precision } \\
\hline $\begin{array}{l}\text { Inter-assay precision } \\
\text { (\%CV of endpoint } \log _{10} \text { titer) }\end{array}$ & $9.3 \%$ \\
\hline $\begin{array}{l}\text { Sensitivity (based on affinity- } \\
\text { purified polyclonal antibody) }\end{array}$ & $58.3 \mathrm{ng} / \mathrm{mL}$ (in well concentration) \\
\hline Drug interference & $\begin{array}{l}\text { PC antibody was detected in } \\
\text { the presence of } \leq 1.0 \mu \mathrm{g} / \mathrm{mL}\end{array}$ \\
\hline $\begin{array}{l}\text { Matrix selectivity (recovery) } \\
\text { with PCs }\end{array}$ & $\begin{array}{l}\text { All unspiked samples generated signal } \\
\text { below the cut point showing negative } \\
\text { result; } 100 \% \text { of the ALL lots had } \\
\text { recovery of neutralizing antibodies } \\
\text { between } 70 \% \text { and } 130 \%\end{array}$ \\
\hline \multirow[t]{3}{*}{ Stability (PC) } & 21-h ambient temperature \\
\hline & 5 freeze/thaw cycles at $-70^{\circ} \mathrm{C}$ \\
\hline & 5 freeze/thaw cycles at $-20^{\circ} \mathrm{C}$ \\
\hline Stability (cell passage numbers) & $\leq 22$ passages \\
\hline
\end{tabular}

$\% C V$ coefficient of variation, $A L L$ acute lymphoblastic leukemia, InO inotuzumab ozogamicin, $P C$ positive control

of surrogate PC antibodies. The results of all validation parameters are highlighted in Table 3.

\section{Non-Hodgkin lymphoma anti-inotuzumab ozogamicin antibody enzyme-linked immunosorbent assay}

An ELISA method used early in development of $\mathrm{InO}$ was applied in support of initial NHL studies. In the assay, an arbitrary floating cut point factor of 2.0 was used. The ELISA method used to support later NHL studies used a statistically derived cut point factor of 1.48, which was based on analysis of 20 individual NHL sera and the $95 \%$ upper confidence limit. Drug tolerance results indicated that the $\mathrm{Rb}$ anti-G544 serum PC antibody titer was impacted by InO concentrations $\geq 0.01 \mu \mathrm{g} / \mathrm{mL}$. Based on results from an affinity-purified anti-G544 antibody, relative assay sensitivity was estimated to be $1690 \mathrm{ng} / \mathrm{mL}$ in $100 \%$ serum when a cut point factor of 2 was used, which improved to $80 \mathrm{ng} / \mathrm{mL}$ with a statistically derived cut point of 1.48 . Results of validation parameters are summarized in Tables 4 and 5 .

Non-Hodgkin lymphoma anti-rituximab binding antibody enzyme-linked immunosorbent assay

An ELISA method used to evaluate presence of antirituximab antibodies during the early development period of InO was applied in support of NHL studies. In the assay, an arbitrary floating cut point factor of 2.0 was used. Based on performance of the purified goat antihuman IgG PC antibody, the mass-based sensitivity of the assay is estimated to be $0.29 \mathrm{ng} / \mathrm{mL}$ in serum. Drug tolerance results indicated that the goat antihuman IgG $\mathrm{PC}$ antibody titer was impacted by the presence of rituximab and $\mathrm{InO}$ at concentrations $\geq 0.01 \mu \mathrm{g} / \mathrm{mL}$. As part of the assay validation, the impact of circulating drug on the ability to detect ADA was assessed. The PC was detected in the presence of $\leq 0.1 \mu \mathrm{g} / \mathrm{mL}$ rituximab and $\leq$ $10 \mu \mathrm{g} / \mathrm{mL}$ InO. Results of validation parameters are summarized in Table 6.

\section{Immunogenicity results from acute lymphoblastic leukemia studies}

For the early phase $1 / 2$ study, clinical samples from a total of 72 ALL patients were tested for binding antibodies in the ADA assay at a scheduled visit. In the screening assay, 4 of the 72 subjects exhibited preexisting ADAs of low titer, which were not confirmed positive by the confirmatory assay. No antibodies were detected in any of the patients after InO treatment. Overall, no patients tested positive for ADAs before or after treatment with $\mathrm{InO}$ during this study (Gorovits et al., 2014).

In the phase 3 pivotal study, anti-InO antibodies were detected in 7 of 164 (4\%) ALL patients. Five of the 7 patients had low-titer antibodies at predose that became undetectable during the course of the study. In 6 of these 7 patients, the antibodies were specific for the calicheamicin portion of InO based on the competition with calicheamicin resulting in a diminished assay signal that was not observed with the G544 portion of the molecule. One patient had anti-G544 antibodies with competition results only slightly higher than cut point. One patient with anti-InO antibodies at the end of treatment had a mixed response to calicheamicin and G544. In total, 2 of 164 (1.2\%) patients exhibited positive ADAs de novo following treatment with InO. Neutralizing antibodies were not detected in any of the 7 patients (Gorovits et al., 2014).

\section{Immunogenicity results from non-Hodgkin lymphoma studies}

In the NHL studies, the immunogenicity rate was calculated using data from patients who exhibited a positive $\mathrm{ADA}$ at any time during the studies regardless of baseline ADA status. Overall, positive ADAs against InO were observed in 27 of 630 (4.3\%) patients with relapsed or refractory NHL. No assessment of neutralizing antibodies to InO in serum was performed in these patients because the analytic method was not available at the time these studies were conducted.

In NHL studies of InO administered concomitantly with rituximab, there were 5 patients with positive antirituximab antibody titers in serum; however, all occurred predose, during cycle 1 before $\mathrm{InO}$ and rituximab 
Table 4 Anti-InO antibody ELISA validation characteristics

\begin{tabular}{|c|c|c|}
\hline \multirow[t]{2}{*}{ PC } & \multicolumn{2}{|c|}{$\begin{array}{l}\text { PC1: Rabbit Anti-G544 Polyclonal Antibody } \\
\text { PC2: Rabbit Anti-Calicheamicin Polyclonal Antibody }\end{array}$} \\
\hline & PC1 & PC2 \\
\hline Intra-assay precision (\%CV of endpoint $\log _{10}$ titer) & $\leq 1.8 \%$ & N/A \\
\hline Inter-assay precision (\%CV of endpoint $\log _{10}$ titer) & $1.8 \%$ & N/A \\
\hline Sensitivity (based on affinity-purified polyclonal antibody) & \multicolumn{2}{|c|}{$224 \mathrm{ng} / \mathrm{mL}$} \\
\hline Drug interference & $\begin{array}{l}\leq 0.01 \mu \mathrm{g} / \mathrm{mL} \operatorname{lnO} \\
\leq 1000 \mu \mathrm{g} / \mathrm{mL} \text { rituximab }\end{array}$ & $\begin{array}{l}\leq 0.1 \mu \mathrm{g} / \mathrm{mL} \operatorname{lnO} \\
\mathrm{N} / \mathrm{A}\end{array}$ \\
\hline Stability (PC1 and PC2) & \multicolumn{2}{|c|}{$\begin{array}{c}3 \mathrm{~h} \text { at room temperature } \\
3 \text { freeze/thaw cycles at }-70{ }^{\circ} \mathrm{C}\end{array}$} \\
\hline
\end{tabular}

\%CV coefficient of variation, ELISA enzyme-linked immunosorbent assay, InO inotuzumab ozogamicin, $N / A$ not applicable, $P C$ positive control

treatment. The immunogenic potential for rituximab to form anti-rituximab antibodies when coadministered with $\mathrm{InO}$ appears to be low.

\section{Assessment of the impact of immunogenicity induction on pharmacokinetics}

The impact of immunogenicity on InO pharmacokinetics (PK) was assessed using post-hoc clearance (CL) derived from the population $\mathrm{PK}$ analysis in patients with ALL. A patient was considered to be ADA-negative if they tested negative for anti-InO ADAs anytime during the study, including at predose (baseline), and was considered ADA-positive if they had $\geq 1$ positive ADA at any time during the study. The analysis indicated that immunogenicity status had no effect on CL of InO (Fig. 4). Because of the limited number of patients testing positive for ADAs, an assessment of efficacy and safety endpoints by ADA status was not performed.

\section{Discussion}

Inotuzumab ozogamicin is a member of the ADC modality. InO is composed of $100 \%$ human constant regions in both heavy and light chains of the antibody and $100 \%$ human framework regions of the variable domains in both heavy and light chains of the antibody. The point mutation (S229P) in the hinge region, intended to stabilize covalent dimerization of the heavy chains, has been included in the sequence of other Pfizer mAb- calicheamicin conjugates, including the formerly licensed product gemtuzumab ozogamicin (Mylotarg ${ }^{\circ}$ ). The calicheamicin moiety of InO contains carbohydrate structures that may react with IgM anti-carbohydrate antibodies present in some patients (Wensel, 2012). Thus, some patients may have pre-existing antibodies reactive with $\mathrm{InO}$.

Evaluating immunogenicity is a critical component of the clinical development of large-molecule biotherapeutics. The development of ADAs may have profound consequences on the PK of a drug, as well as its safety and/ or efficacy (Hoofring et al., 2013; Sauerborn \& van Dongen, 2014). In this bioanalytical analysis for InO, a bridging ECL and a cell-based assay were used to detect ADAs and neutralizing antibodies, respectively, in patients with ALL. ELISA methods were used to detect ADAs to InO and anti-rituximab antibodies in patients with NHL. When InO was coadministered with rituximab, 2 independent anti-InO and anti-rituximab ELISA methods were developed and validated. The ELISA for $\mathrm{InO}$ provided adequate sensitivity $(200 \mathrm{ng} / \mathrm{mL} \mathrm{mAb}$ equivalent) with relatively poor drug tolerance; interference from free circulating drug was observed at $100 \mathrm{ng} / \mathrm{mL}$. However, in NHL studies, trough circulating drug levels were $<100 \mathrm{ng} / \mathrm{mL}$, therefore likely not impacting anti-InO antibody detection. In contrast to ELISA, the ECL assay had significantly improved drug tolerance, $500 \times$ higher to $50 \mu \mathrm{g} / \mathrm{mL}$.

Table 5 Anti-InO antibody ELISA validation characteristics

\begin{tabular}{lll}
\hline PC & \multicolumn{2}{l}{ PC1: Rabbit Anti-G544 Polyclonal Antibody } \\
& \multicolumn{1}{c}{ PC2: Rabbit Anti-Calicheamicin Polyclonal Antibody } \\
\cline { 2 - 3 } & PC1 & PC2 \\
\hline Intra-assay precision (\%CV of endpoint $\log _{10}$ titer) & $\leq 1.07 \%$ & $\mathrm{~N} / \mathrm{A}$ \\
Inter-assay precision (\%CV of endpoint $\log _{10}$ titer) & $6.23 \%$ & $\mathrm{~N} / \mathrm{A}$ \\
Sensitivity (based on affinity-purified polyclonal antibody) & $0.080 \mu \mathrm{g} / \mathrm{mL}$ & $32.7 \mu \mathrm{g} / \mathrm{mL}$ \\
Drug interference & Not reassessed & Not reassessed \\
Stability & 24 h ambient & Not reassessed \\
\hline
\end{tabular}

\%CV coefficient of variation, ELISA enzyme-linked immunosorbent assay, InO inotuzumab ozogamicin, N/A not applicable, $P C$ positive control 
Table 6 Anti-rituximab antibody assay validation characteristics

\begin{tabular}{ll}
\hline Positive Control & Goat Antihuman IgG Antibody \\
\hline $\begin{array}{l}\text { Intra-assay precision } \\
\text { (\%CV of endpoint } \log _{10} \text { titer) }\end{array}$ & $0.5 \%$ \\
$\begin{array}{l}\text { Inter-assay precision } \\
\text { (\%CV of endpoint } \log _{10} \text { titer) }\end{array}$ & $1.8 \%$ \\
$\begin{array}{l}\text { Sensitivity (based on affinity-purified } \\
\text { polyclonal antibody) }\end{array}$ & $0.29 \mathrm{ng} / \mathrm{mL}$ \\
Drug interference & $\leq 0.1 \mu \mathrm{g} / \mathrm{mL}$ rituximab \\
& $\leq 10 \mu \mathrm{g} / \mathrm{mL} \operatorname{lnO}$ \\
Stability & $4 \mathrm{~h} \mathrm{ambient}$ \\
& 5 freeze/thaw cycles at $-70{ }^{\circ} \mathrm{C}$
\end{tabular}

$\% C V$ coefficient of variation, $\lg \mathrm{G}$ immunoglobulin $\mathrm{G}, \ln \mathrm{O}$

inotuzumab ozogamicin

Electrochemiluminescence bridging assay platforms have successfully been used for other approved ADCs, such as Kadcyla (Genentech; South San Francisco, CA) (Carrasco-Triguero et al., 2013). The antibody response measured by the ECL assay in ALL studies was largely reactive to calicheamicin moiety of the $\mathrm{InO}$. This observation was not unexpected because calicheamicin is a naturally occurring compound. Gemtuzumab ozogamicin $\left(\right.$ Mylotarg $\left.{ }^{\circ}\right)$, used in the treatment of acute myelogenous leukemia, was the first monoclonal ADC linking calicheamicin to an $\mathrm{mAb}$ and the first FDAapproved ADC. ADAs to the calicheamicin-linker portion of gemtuzumab ozogamicin developed in 2 of 40 patients in a single phase 1 study, whereas no patients $(0$ of 142) developed ADAs to gemtuzumab ozogamicin in a pooled analysis of phase 2 studies (Wyeth-Ayerst, 2000; Sievers et al., 2001).

Immunogenicity assays were designed to obtain low false-negatives in anticipation of eliminating false-

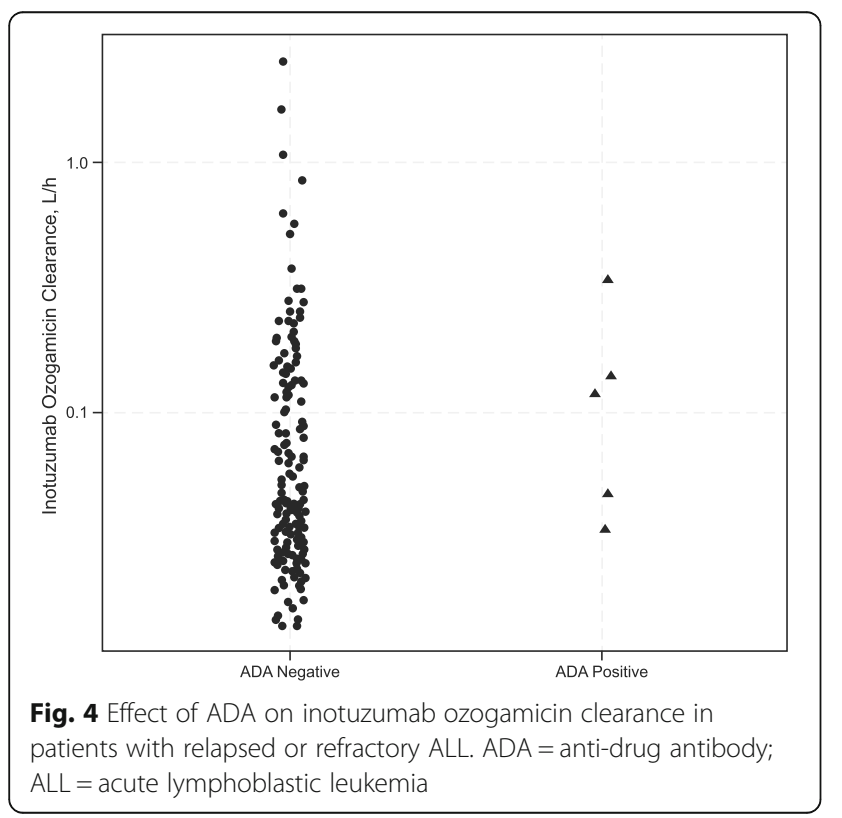

positive results by confirmatory assays with the threshold statistically calculated to provide $1 \%$ false-positive samples in the assay. Overall, the immunogenicity incidence rate observed in the pivotal ALL study was low (4\%).

Antibodies detected against InO using the ECL assay were further characterized for neutralizing activity using an antiproliferative cell-based assay. The assay was validated according to current industry recommendations. The assay reportable sensitivity was $580 \mathrm{ng} / \mathrm{mL}$ and drug tolerance of approximately $1 \mu \mathrm{g} / \mathrm{mL}$. No neutralizing activity was detected in the ADA-positive study samples.

A definitive assessment of the relationship between ADA response and clinical safety or efficacy endpoints could not be established because of the limited number of ADA-positive patients. No noticeable difference was observed in the $\mathrm{CL}$ of $\mathrm{InO}$ when comparing ADApositive and ADA-negative patients with ALL. This evaluation indirectly confirms the lack of neutralizing activity of ADAs.

It has been well described that antibody detection is highly dependent on the sensitivity and specificity of the assay. Additionally, the detection of antibodies, including neutralizing antibody positivity, in an assay may be influenced by several factors including assay methodology, sample handling, timing of sample collection, concomitant medications, and underlying disease. For these reasons, comparing the incidence of antibodies to $\mathrm{InO}$ in the studies described herein with the incidence of antibodies to other products may be misleading. Published data show that the immunogenicity binding antibody rates range from $0 \%$ to $30 \%$ (Hock et al., 2015). In addition, CarrascoTriguero reported a $4.3 \%$ incidence rate in a phase 3 clinical study of Kadcyla, (ado-trastuzumab emtansine [TDM1]); however, the neutralizing antibody rate was not published (Carrasco-Triguero et al., 2013). In light of the published data, the InO ADA incidence rate reported in this study is in line with the rates reported in other studies.

\section{Conclusions}

Based on the relatively low perceived immunogenicity risk for this product, the standard recommended approach to ADA testing was used during the clinical studies (Center for Drug Evaluation and Research, US Food and Drug Administration, 2009; Committee for Medicinal Products for Human Use, 2007). Immunogenicity response to $\mathrm{InO}$ was measured using 2 separate bridging platforms in NHL and ALL studies. Samples for immunogenicity assessments were collected based on time points specified in each individual clinical study. During early NHL studies, immunogenicity response was measured using an ELISA platform, which was considered a standard of practice at the time, for the detection of 
anti-InO or anti-rituximab antibodies. Independent antiInO and anti-rituximab ELISA methods were developed and validated according to the scientific experience and best practices of laboratories where the assays were developed. In the later ALL studies, MSD-based bridging ECL assay was developed and validated according to recommendations from the regulatory industry and scientific experience (Center for Drug Evaluation and Research, US Food and Drug Administration, 2009; Committee for Medicinal Products for Human Use, 2007; Hoofring et al., 2013; Jani et al., 2015; Shankar et al., 2008). Similar bridging assay platforms have successfully been used for other approved ADCs (CarrascoTriguero et al., 2013). The antibody response was also characterized to determine the specificity for binding to the G544 antibody or calicheamicin moieties of InO because each domain may invoke an immunogenicity response (Gorovits et al., 2014). Additional evaluation of neutralizing activity was conducted using a cell-based assay. In NHL trials, ADAs were detected in patients and neutralizing antibody assays were not yet available. In the ALL pivotal study, ADAs were detected in patients, but no neutralizing antibodies were detected. Immunogenicity status had no impact on InO PK clearance. The comprehensive strategy allowed detection of immune response to ADC and demonstrated no neutralizing activity to $\mathrm{InO}$.

\footnotetext{
Abbreviations

$\% C V$ : Coefficient of variation; ADA: Anti-drug antibody; ADC: Antibody-drug conjugate; ALL: Acute lymphoblastic leukemia; CCP: Confirmatory/ characterization cut point; CL: Clearance; DMH: Dimethyl hydrazide; ECL: Electrochemiluminescence; ELISA: Enzyme-linked immunosorbent assay; EOT: End of treatment; HPC: High positive control; HRP: Avidin-horseradish peroxidase; IgG4: Immunoglobulin G4; InO: Inotuzumab ozogamicin; mAb: Monoclonal antibody; MRD: Minimum required dilution; MSD: Meso Scale Discovery; N/A: Not applicable; NC: Negative control; NHL: NonHodgkin lymphoma; OD: Optical density; PC: Positive control; PK: Pharmacokinetics; Rb: Rabbit; RLU: Relative light unit; SCP: Screen cut point; SCPF: Screen cut point factor; SD: Standard deviation; TMB: 3, 3', 5, 5' tetramethylbenzidine
}

\section{Acknowledgments}

The authors thank Brian Hee of Pfizer Inc for bioanalytical support. Editorial support was provided by Kevin O'Regan, PhD, of Complete Healthcare Communications, LLC (West Chester, PA), a CHC Group company, and was funded by Pfizer Inc.

\section{Funding}

This study was sponsored by Pfizer Inc.

\section{Availability of data and materials}

Data generated or analyzed during this study are included in this manuscript.

\footnotetext{
Authors' contributions

Conception and design: DJ. Acquisition of data (provided animals, acquired and managed patients, provided facilities, etc.): DJ, JN, BG. Analysis and interpretation of data (eg, statistical analysis, biostatistics, computational analysis): DJ, JN. Writing, review, and/or revision of the manuscript: DJ, JN, YC, JB, BG. Administrative, technical, or material support (ie, reporting or organizing data, constructing databases): DJ, JN, BG. All authors read and approved the final manuscript.
}

\section{Competing interests}

$D J, J N, Y C, J B$, and BG were stockholders and employees of Pfizer Inc at the time of study.

\section{Publisher's Note}

Springer Nature remains neutral with regard to jurisdictional claims in published maps and institutional affiliations.

\section{Author details}

'Pfizer Inc, 610 N. Main Street, Cambridge, MA 02142, USA. ${ }^{2}$ Pfizer Inc, 1 Burtt Road, Andover, MA, USA. ${ }^{3}$ Pfizer, La Jolla, CA, USA. ${ }^{4}$ Pfizer Inc, Collegeville, PA, USA.

Received: 10 October 2017 Accepted: 15 January 2018

Published online: 07 February 2018

\section{References}

Advani A, Coiffier B, Czuczman MS, Dreyling M, Foran J, Gine E et al (2010) Safety, pharmacokinetics, and preliminary clinical activity of inotuzumab ozogamicin, a novel immunoconjugate for the treatment of B-cell non-Hodgkin's lymphoma: results of a phase I study. J Clin Oncol 28:2085-2093

Alley SC, Okeley NM, Senter PD (2010) Antibody-drug conjugates: targeted drug delivery for cancer. Curr Opin Chem Biol 14:529-537

Carrasco-Triguero M, Yi JH, Dere R, Qiu ZJ, Lei C, Li Y et al (2013) Immunogenicity assays for antibody-drug conjugates: case study with ado-trastuzumab emtansine. Bioanalysis 5:1007-1023

Center for Drug Evaluation and Research, US Food and Drug Administration. Guidance for Industry: Assay Development for Immunogenicity Testing of Therapeutic Proteins. 2009. http://www.bioagilytix.com/wp-content/uploads/ 2016/02/FDA-GUIDANCE-Assay-Development-Immunogenicity-Testing.pdf . Accessed 27 June 2017

Committee for Medicinal Products for Human Use. Guideline on immunogenicity assessment of biotechnology-derived therapeutic proteins. London: European Medicines Agency; December 13, 2007. EMEA/CHMP/BMWP/14327/2006

DeAngelo D, Stock W, Stein A, Shustov A, Liedtke M, Schiffer C et al (2017) Inotuzumab ozogamicin in adults with relapsed or refractory CD22-positive acute lymphoblastic leukemia: a phase 1/2 study. Blood Adv 1:1167-1180

Fayad L, Offner F, Smith MR, Verhoef G, Johnson P, Kaufman JL et al (2013) Safety and clinical activity of a combination therapy comprising two antibodybased targeting agents for the treatment of non-Hodgkin lymphoma: results of a phase $1 / /$ study evaluating the immunoconjugate inotuzumab ozogamicin with rituximab. J Clin Oncol 31:573-583

Gorovits B, Wakshull E, Pillutla R, Xu Y, Manning MS, Goyal J (2014) Recommendations for the characterization of immunogenicity response to multiple domain biotherapeutics. J Immunol Methods 408:1-12

Hock MB, Thudium KE, Carrasco-Triguero M, Schwabe NF (2015) Immunogenicity of antibody drug conjugates: bioanalytical methods and monitoring strategy for a novel therapeutic modality. AAPS J 17:35-43

Hoofring SA, Lopez R, Hock MB, Kaliyaperumal A, Patel SK, Swanson SJ et al (2013) Immunogenicity testing strategy and bioanalytical assays for antibodydrug conjugates. Bioanalysis 5:1041-1055

Jani D, Marsden R, Mikulskis A, Gleason C, Klem T, Krinos Fiorotti C et al (2015) Recommendations for the development and validation of confirmatory antidrug antibody assays. Bioanalysis 7:1619-1631

Kantarjian HM, DeAngelo DJ, Stelljes M, Martinelli G, Liedtke M, Stock W et al (2016) Inotuzumab ozogamicin versus standard therapy for acute lymphoblastic leukemia. N Engl J Med 375:740-753

Koren E, Zuckerman LA, Mire-Sluis AR (2002) Immune responses to therapeutic proteins in humans-clinical significance, assessment and prediction. Curr Pharm Biotechnol 3:349-360

Ogura M, Tobinai K, Hatake K, Davies A, Crump M, Ananthakrishnan R et al (2016) Phase I study of inotuzumab ozogamicin combined with R-CVP for relapsed/ refractory CD22+ B-cell non-Hodgkin lymphoma. Clin Cancer Res 22:4807-4816

Sauerborn M, van Dongen W (2014) Practical considerations for the pharmacokinetic and immunogenic assessment of antibody-drug conjugates BioDrugs 28:383-391

Shankar G, Devanarayan V, Amaravadi L, Barrett YC, Bowsher R, Finco-Kent D et al (2008) Recommendations for the validation of immunoassays used for detection of host antibodies against biotechnology products. J Pharm Biomed Anal 48:1267-1281 
Shor B, Gerber HP, Sapra P (2015) Preclinical and clinical development of inotuzumabozogamicin in hematological malignancies. Mol Immunol 67:107-116

Sievers EL, Larson RA, Stadtmauer EA, Estey E, Lowenberg B, Dombret $\mathrm{H}$ et al (2001) Efficacy and safety of gemtuzumab ozogamicin in patients with CD33positive acute myeloid leukemia in first relapse. J Clin Oncol 19:3244-3254 Teicher BA, Chari RV (2011) Antibody conjugate therapeutics: challenges and potential. Clin Cancer Res 17:6389-6397

Wensel DL, Awwad M, inventors. Wyeth Corp., assignee. Elimination of interference in immunoassays caused by anti-carbohydrate antibodies.: South African patent CA2686206. May 7, 2012

Wyeth-Ayerst. Gemtuzumab Ozogamicin Summary for Presentation to the FDA's Oncologic Division Advisory Committee 2000 http://www.fda.gov/ohrms/ dockets/ac/00/backgrd/3592b2c.pdf. Accessed 23 Jan 2017

Zein N, Sinha AM, McGahren WJ, Ellestad GA (1988) Calicheamicin gamma 11: an antitumor antibiotic that cleaves double-stranded DNA site specifically. Science 240:1198-1201

\section{Submit your manuscript to a SpringerOpen ${ }^{\circ}$ journal and benefit from:}

- Convenient online submission

- Rigorous peer review

- Open access: articles freely available online

- High visibility within the field

- Retaining the copyright to your article

Submit your next manuscript at $\boldsymbol{s p r i n g e r o p e n . c o m ~}$ 